\title{
A global survey of licensing restrictions for drivers with diabetes
}

\author{
SALEM A BESHYAH, ${ }^{1}$ ANAS S BESHYAH,${ }^{2}$ SALIM YAGHI, ${ }^{2}$ WALEED $S$ BESHYAH, ${ }^{2}$ BRIAN M FRIER ${ }^{3}$
}

\begin{abstract}
Background: Ensuring medical fitness to drive is an important safety measure for people with diabetes and is a prerequisite for a driving licence in many countries.

Objectives: To ascertain the current regulatory restrictions on drivers with diabetes currently being applied internationally. Methods: An electronic survey (in English) was sent to contacts of member organisations of the International Diabetes Federation and to selected specialists in diabetes. Questions addressed the regulations in place for insulin-treated drivers. Results: Information on licensing was obtained from 85 countries. No restrictions on drivers with insulin-treated diabetes existed in 59 countries (69.4\%). Medical assessment of some type was required in 29 countries (34.5\%). They were performed by different people and at different time intervals. Emphasis was placed on conditions causing potential risk to driving safety. When insulin is introduced to a licensed driver's treatment, in most countries the driver is permitted to continue driving without any change in licensing entitlement $(n=68 ; 80 \%)$; in 16 countries (19\%) a driver can retain their driving licence subject to special conditions and in one country the driver will have the driving licence revoked permanently. With respect to large goods vehicles and passenger-carrying vehicles, no restrictions or assessments are required for drivers with insulin-treated diabetes in most responding countries $(n=56 ; 66 \%)$; licensing is permitted with some restriction in 23 countries $(27 \%)$ and prohibited in six countries $(7 \%)$.

Conclusions: There is a wide variation between different countries and global regions in the statutory requirements and policies used to regulate and assess drivers with diabetes. The lack of regulation in many countries may adversely affect public safety.

Br J Diabetes 2017;17:3-10
\end{abstract}

Center for Diabetes and Endocrinology, Sheikh Khalifa Medical City, Abu Dhabi, UAE

Institute of Medicine, Sheikh Khalifa Medical City, Abu Dhabi, UAE

The Queen's Medical Research Institute, University of Edinburgh,

Edinburgh, Scotland, UK

Address for correspondence: Dr Salem A Beshyah

Consultant Diabetologist/Endocrinologist, Center for Diabetes and

Endocrinology, Sheikh Khalifa Medical City, PO Box 59472, Abu Dhabi,

United Arab Emirates

Tel: 00971505662723

E-mail: beshyah@yahoo.com

http://dx.doi.org/10.15277/bjd.2017.117
Key words: driving, diabetes mellitus, licensing regulations, insulin, hypoglycaemia, medical fitness to drive

\section{Introduction}

Both the prevalence of diabetes and the ownership of motor vehicles are increasing in most countries, although the incremental rates vary in different parts of the world and are associated with economic status. Both measures are rising rapidly in underdeveloped regions, where the rates of death and injuries from road traffic accidents are highest. ${ }^{1}$ In many parts of the world the use of private cars is the main method of transport. Although medical conditions represent a relatively small proportion of the causes of motor vehicle accidents, public safety in relation to driving requires effective assessment of medical fitness to drive. Diabetes is considered to be a prospective medical disability in that problems can develop over time. For drivers with insulintreated diabetes, the main problems are the risk of hypoglycaemia and adverse effects of complications such as sight-threatening retinopathy. ${ }^{2-4}$ If hypoglycaemia occurs while driving a motor vehicle, the development of cognitive dysfunction causes deterioration in driving performance and is recognised to be a cause of motor vehicle accidents. . $^{5-7}$

Efforts to limit the effects of these potential diabetes-related problems have been addressed in developed countries by the imposition of regulatory policies and development of statutory requirements for the issue of driving licences. Efforts to harmonise driving regulations have been made by governments within some geopolitical regions such as Europe, North America and Australia. ${ }^{8-10}$ However, the political and social concerns about road safety in relation to many medical disorders, of which diabetes is only one example, are not shared globally and there is little, if any, degree of uniformity. Many countries in the developing world make no provision to either assess medical fitness to drive or restrict the driving licences of people with insulintreated diabetes. A small survey of driving licensing practice in 24 countries was conducted over 20 years ago ${ }^{11}$ and demonstrated considerable heterogeneity, with some countries imposing no restrictions whatsoever and exhibiting a lack of concern and interest in this problem. ${ }^{12,13}$ No subsequent concerted international effort has been made to introduce measures directed to limit potential risks associated with drivers who are treated with insulin. The present international survey was undertaken in an attempt to ascertain the current regulatory restrictions on drivers with diabetes in different regions of the world and in individual countries, to provide an update on the present situation and to inform a possible international call for action. 


\section{Methods}

\section{Rationale and objectives}

The aim of the present global survey was to ascertain the current state of statutory restrictions and practices in different countries with respect to driving and diabetes.

\section{Survey questionnaire}

A total of nine survey questions were developed de novo to serve the objectives of the study (Table 1). They addressed whether or not people with diabetes who require treatment with insulin are permitted to drive in an individual country. If people with insulintreated diabetes are eligible to receive a licence to drive, information was requested about the necessary requirements for a licence to be issued, and to determine whether any restrictions are placed on driving commercial motor vehicles (described collectively in lay terms as lorries, trucks and taxis). The questionnaire sought to identify: (a) the responders' capacity, relevant country and International Diabetes Federation (IDF) region; (b) the general restrictions on driving imposed on people with diabetes; (c) the process of evaluation of medical fitness to drive of people with diabetes and risk assessment of various aspects of diabetes complications and treatment; (d) if a change in status occurs should an established driver with diabetes require conversion to insulin therapy; and (e) restrictions imposed on driving large goods vehicles and vehicles of public transportation.

\section{Survey management}

The survey was powered by a commercial provider (Survey
Monkey Inc, USA). Email invitations that explained the purposes of the study and included the full name, credentials, affiliation and contact details of the principal investigator were sent to all the member organisations of the IDF as listed on the IDF website. At the time of the survey the IDF had 229 member organisations representing 170 countries. All member organisations with an available email address on the website were contacted and, where a country was represented by more than one member organisation, all of the individual members were contacted. The link was unique to the survey and tied to the individual email address. Reminders were sent to non-responding members and the survey was further supported by invitations to selected experts in many countries.

\section{Data and statistical analysis}

Responses were reconciled on a country basis and data were expressed in actual numbers in proportion to totals or were adjusted as percentages. Data are presented on global and regional bases as appropriate as these issues are mostly discussed as such in regional forums. Furthermore, as a post hoc examination, review was made as to whether licences for drivers on insulin are restricted according to relevant national social/political/economic indices such as Gross Domestic Product (GDP) as a measure of socioeconomic development and Road Traffic Fatality (RTF) rate per 100,000 population as an index of driving standards and safety using global data published by the World Bank and the World Health Organisation, respectively. ${ }^{14,15}$

Table 1 Global survey of the licensing restrictions imposed on drivers with diabetes. Phrasing of the questionnaire and expected/ possible responses

Q1. I am answering the questions in the survey in the following capacity (Responses: IDF member organisation, invited expert, regulatory body, an investigator extracting information from an internet website, a patient of relative who is confidently familiar with the regulations)

Q2. I am responding to these questions in the following context (Responses: country; IDF region)

Q3. What are the rules in effect at the time of survey for insulin-treated drivers of motor vehicles in the responding country: please choose by choosing the appropriate answers. In your country (only one can be chosen). (Responses: no restrictions at all on licensing of people with diabetes; licensing is allowed but only if special requirements were met, complete ban on the licensing of drivers who use insulin).

Q4. If your country permits people with diabetes to drive under special conditions, please indicate if a medical examination is required for prospective or current drivers who take insulin. (Responses: yes, no, not applicable).

Q5. If your country permits people with diabetes to drive under special conditions and imposes a medical assessment, please indicate the time frame in which this examination was conducted (Responses: once at time of application only; every 5 years; every 3 years; annually, not applicable, others*).

Q6. If your country permits people with diabetes to drive under special conditions and imposes a medical assessment, please indicate the evaluation arrangement (Responses: review and approval from a designated medical advisory panel is required, any medical professional can adequately certify, or both are required, not applicable, other*).

Q7. If your country permits people with diabetes to drive under special conditions and imposes a medical assessment, please indicate the emphasis of the evaluation (Responses: hypoglycaemia, hypoglycaemia unawareness, neuropathy, impairment of vision (acuity or field), neuromuscular coordination, not applicable, other*)

Q8. What will happen if an established driver begins to use insulin in the treatment of diabetes? (Responses: their licence is revoked, driver allowed licensing under special condition, driver allowed to continue to drive without any change in his or her licensing)

Q9: For lorry and taxi drivers with diabetes who are treated with insulin, please indicate the status of the licensing regulations (Responses: licensing permitted with no restrictions; licensing not permitted; licensing permitted with restrictions)

* More space is given for additional information/options. 


\section{Results}

\section{Sources of responses}

Responses from 85 countries were received. The sources of the received responses were as follows: 63 (74.1\%) from members of the IDF, $20(23.3 \%)$ from invited experts and two responses (2.4\%) were received from government health service bodies. The responders were distributed around different regions of the world (Figure 1). Based on the IDF regions, these represented countries in Africa (16), the Middle East and North Africa (MENA; 16), Europe (19), North America and the Caribbean (NAC; 12), the Western Pacific region (WPR; 8), South and Central America (SACA; 9) and South East Asia (SEA; 5) (Table 2). The responders which had robust systems for driving licensing and assessment of medical fitness to drive were Australia, Canada, Germany, Ireland, the UK and the USA. Invited experts were the main source of information in some regions such as MENA (75\%) and SEA (50\%). Multiple responses pertaining to a single country were very uncommon and, when these did occur, responses were examined carefully with no conflicts being found.

\section{General restrictions}

Fifty-nine respondents (69.4\%) reported that no restrictions are imposed on drivers with diabetes, 25 respondents $(29.4 \%)$ reported that restrictions are in place for drivers with insulintreated diabetes and one country currently imposes a total ban on the issue of licences for insulin-treated drivers.

\section{Medical evaluations}

Medical examination of some type is required in 29 countries (34.5\%) but not in the others. When required, it is performed once only (3.9\%), annually $(7.7 \%)$, every 2 years $(2.6 \%)$, every 3 years $(12.8 \%)$, every 5 years $(2.6 \%)$ or at discretionary times $(3.9 \%)$ as determined by a police officer or licensing officer when driving safety is thought to be at risk. Other factors considered were age, nature of licensing, quality of glycaemic control and previous accidents, which were stated to alter the frequency of assessments $(5.2 \%)$. The medical assessment could be performed by any medically qualified doctor $(19.3 \%)$, by a designated physician $(12.1 \%)$ or by any physician and later approved by a designated medical board $(6.0 \%)$. Conditions that were considered to impose a serious risk to driving safety in people with diabetes included impaired vision (acuity or field restriction) by $32.5 \%$, a history of hypoglycaemia (unspecified) (22.9\%), impaired awareness of hypoglycaemia $(22.9 \%)$, presence of peripheral neuropathy $(12.1 \%)$ and disorders of neuromuscular incoordination (9.6\%).

\section{Change of licensing status after initiation of insulin}

In response to the question of what occurs if treatment with insulin becomes necessary, 68 respondents $(80.1 \%)$ reported that the driver is allowed to continue to drive without any change in driving privileges or restriction of the driving licence, $16(18.8 \%)$ that the driver is allowed a licence under special

Figure 1. Graphic representation of the global responses to the survey on basis of the regions of The International Diabetes Federation (IDF). For each region, the number of responding /all countries is given under the name of the region followed by percentage (\%) of responses country-wise

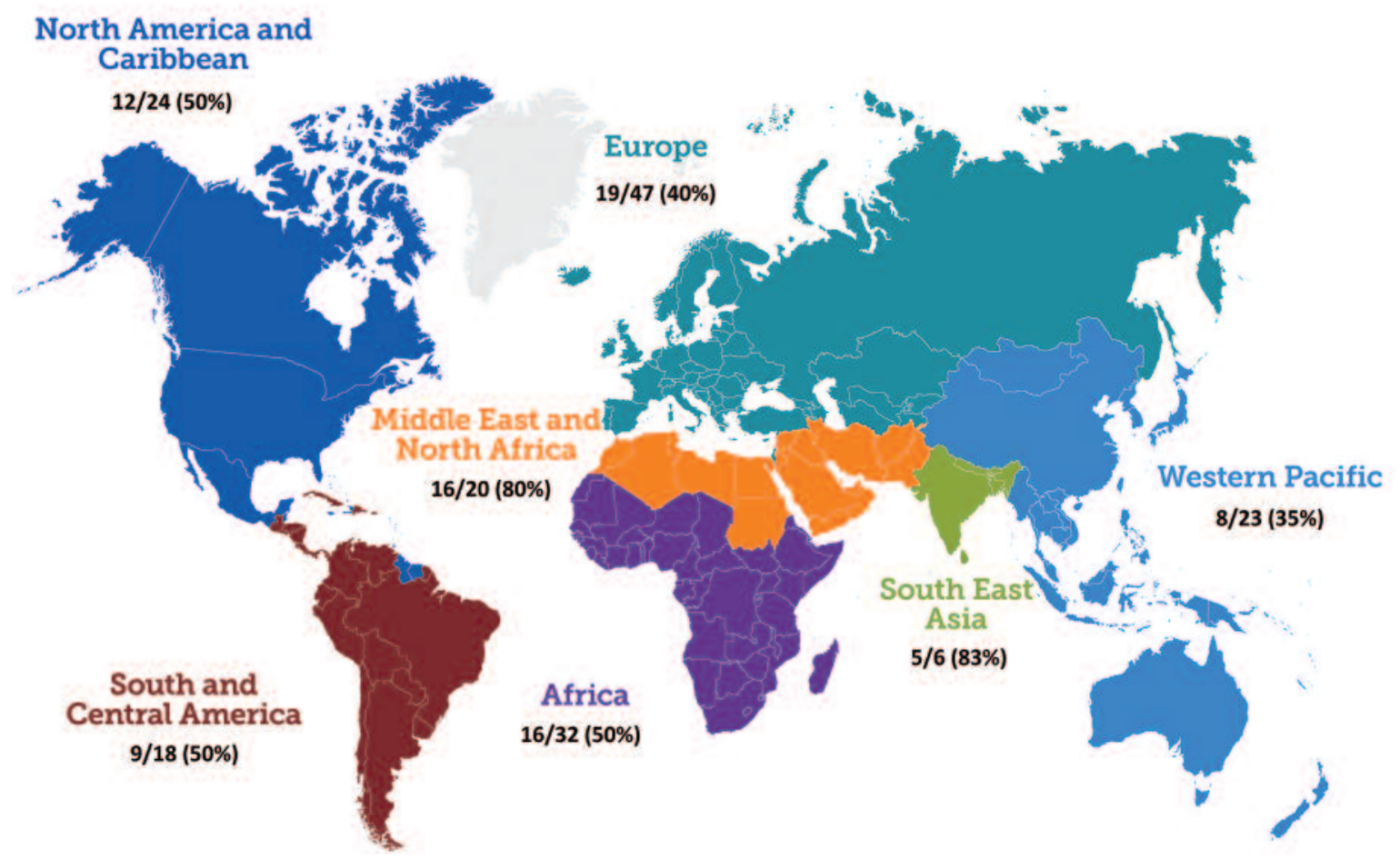


Table 2 Summary of salient findings on the global status of driving restrictions per International Diabetes Federation (IDF) region: IDF membership (countries and organisations), individual countries represented in the responses received per region and number (\%) of countries with restrictions on drivers with diabetes, requirements for medical evaluations and restrictions on lorry and taxi drivers

\begin{tabular}{|c|c|c|c|c|c|c|}
\hline $\begin{array}{l}\text { IDF } \\
\text { regions* }\end{array}$ & $\begin{array}{l}\text { Countries** } \\
\text { (IDF member } \\
\text { organisations) }\end{array}$ & $\begin{array}{l}\text { Responses*** } \\
\mathrm{n}(\%)\end{array}$ & Individual countries represented in responses & $\begin{array}{l}\text { No } \\
\text { restrictions } \\
\text { apply }\end{array}$ & $\begin{array}{l}\text { No } \\
\text { medical } \\
\text { assessment } \\
\text { required }\end{array}$ & $\begin{array}{l}\text { No restrictions } \\
\text { on lorry and } \\
\text { taxi diabetic } \\
\text { drivers }\end{array}$ \\
\hline Africa & $32(35)$ & $16(50 \%)$ & $\begin{array}{l}\text { Botswana, Cameroon, CDR, Côte d'ivoire, Ethiopia, } \\
\text { Ghana, Gambia, Malawi, Nigeria, Rwanda, } \\
\text { South Africa, Seychelles, Togo, Uganda, Zambia, } \\
\text { Zimbabwe }\end{array}$ & $81.3 \%$ & $80.0 \%$ & $87.5 \%$ \\
\hline Europe & $47(68)$ & $19(40 \%)$ & $\begin{array}{l}\text { Albania, Armenia, Austria, Cyprus, France, Germany, } \\
\text { Greece, Ireland, Kazakhstan, Luxembourg, Malta, } \\
\text { Poland, Portugal, Serbia, Slovakia, Slovenia, Sweden, } \\
\text { UK, Uzbekistan }\end{array}$ & $42.1 \%$ & $31.6 \%$ & $26.3 \%$ \\
\hline MENA & $20(23)$ & $16(80 \%)$ & $\begin{array}{l}\text { Algeria, Afghanistan, Bahrain, Egypt, Iraq, Jordan, } \\
\text { KSA, Kuwait, Libya, Morocco, Oman, Pakistan, } \\
\text { Palestine, Qatar, Sudan, UAE }\end{array}$ & $87.5 \%$ & $93.8 \%$ & $80.0 \%$ \\
\hline NAC & $24(27)$ & $12(50 \%)$ & $\begin{array}{l}\text { Anguilla, Bahamas Commonwealth, Barbados, } \\
\text { British Virgin Islands, Canada, Cayman Islands, } \\
\text { Grenada, Guyana, Mexico, Montserrat, St Lucia, USA }\end{array}$ & $75.0 \%$ & $75.0 \%$ & $58.3 \%$ \\
\hline SACA & $18(40)$ & $9(50 \%)$ & $\begin{array}{l}\text { Bolivia, Brazil, Columbia, Costa Rica, Dominican } \\
\text { Republic, Ecuador, El Salvador, Paraguay, Uruguay }\end{array}$ & $77.8 \%$ & $55.6 \%$ & $77.8 \%$ \\
\hline SEA & $6(8)$ & $5(83 \%)$ & Bangladesh, India, Maldives, Mauritius, Sri Lanka & $100 \%$ & $80.0 \%$ & $80.0 \%$ \\
\hline WPR & $23(28)$ & $8(35 \%)$ & $\begin{array}{l}\text { Australia, Fiji, Hong Kong, Malaysia, Mongolia, } \\
\text { New Zealand, Philippines, Singapore }\end{array}$ & $37.5 \%$ & $50 \%$ & $75 \%$ \\
\hline
\end{tabular}

conditions and a single respondent $(1.2 \%)$ reported that the driving licence is revoked permanently.

\section{Status of commercial licensing for drivers with diabetes}

In 56 countries $(66 \%)$, licensing to drive large goods vehicles (trucks and lorries) and taxis is permitted with no restrictions being imposed for drivers receiving treatment with insulin. No specific question was included in the survey on buses. In 23 countries $(27 \%)$, licensing is permitted if defined restrictions are met. In the remaining six countries (7\%), driving licences for lorries and taxis are not issued under any circumstances. However, some respondents indicated distinguishing between licensing terms and conditions for the two groups. Detailed comments were received to this effect from some respondents (Table 3 ). The response relating to the position in the USA indicated that licensing rules for drivers are not uniform throughout the USA and vary between states. The law on driving regulations was changed in 2005 to allow commercial drivers treated with insulin to apply for a driver's exemption provided they had been driving for 3 years before they applied. The medical evaluation process for commercial drivers occurs at predetermined intervals, typically every 2 years. Unlike ordinary driving licences, these regular evaluations are not linked to episodes of severe hypoglycaemia but are part of an ongoing evaluation of medical fitness to drive for jobs that require commercial driving. The Federal government has no diabetes-specific restrictions for individuals who manage their diabetes with diet and/or oral medications. It offers an exemption programme for insulin-using interstate commercial drivers and issues medical certificates to qualified drivers. Factors in the Federal commercial driving medical evaluation include a review of diabetes history, medications, hospitalisations, blood glucose history and tests for various complications and an assessment of drivers' comprehension of diabetes and willingness to monitor their condition.

\section{Relationship of licensing restrictions to socioeconomic development}

Restrictions on licences in drivers on insulin (in general) were examined according to two relevant national social/political/ economic indices (GDP and RTF) (Table 4). GDP was significantly lower in 56 countries with no restrictions than in 25 countries with restrictions $(p=0.001)$. The road traffic fatality rate per 100,000 population was greater in the 56 countries with no restrictions than in the 23 countries with restrictions $(p=0.008)$.

\section{Discussion}

Several medical conditions including diabetes have the potential to interfere with driving performance and so increase the risk of motor 
Table 3 Specific comments made by some respondents on the status of licensing of commercial drivers with diabetes*

Austria: Medical assessments in short intervals (1-3 years) are mandatory. If frequent hypoglycaemia occurs, the medical officer may withdraw the driving license.

\section{Australia: Specialist clearance}

British Virgin Islands: Eye tests are done annually

Canada: Licence will be revoked if hypoglycaemia without symptoms and for inadequate HbA1C

Cyprus: In some cases of insulin users report of the doctors is needed. This matter was raised a long time ago and we suggested that each country have to deal with the appropriate authorities of the country. In case of any diversion from EU many problems will arise. Therefore we suggest that the Association each country made the necessary consultation with the Government and the appropriate authorities concerned. The Ministry of Justice is in the process of new regulations with the Driving Licenses especially for the eldest for the time being the licence is renewed every 3 years

Cayman Islands: Letter from doctor indicating person is fit to drive taxi or lorry is required

Germany: People have to hand in an expert assessment about their medical status and have to meet even higher criteria according hypoglycaemia

Kazakhstan: Not permitted when a driver has impairment of vision, impairment of neuromuscular coordination, hypoglycaemia, diabetic foot complications, nephropathy, high blood pressure or cardiovascular complications

Luxembourg: Licence is permitted, but occupational medicine may not accept people for certain jobs

Mexico: Uncontrolled diabetes, diabetes treated with insulin restricts commercial driving

New Zealand: IDF member organisation: Six-monthly GP review; annual specialist review regular testing - must be able to prove regular meal breaks. Expert comments: (1) A 6-monthly medical certificate from a GP documenting: adherence to treatment - that the medical practitioner has proof of regular self-testing of blood glucose with satisfactory blood glucose levels - the absence of hypoglycaemic episodes or unawareness - the absence of significant diabetic complications. (2) A regular pattern of shifts with adequate meal breaks. (3) A satisfactory annual specialist review

Poland: Two severe hypoglycaemic episodes within a year and/or advanced vascular complications exclude from professional driving.

Portugal: License is permitted to taxi drivers. A complete ban on the licensing of lorry drivers with diabetes

Slovenia: They must respect the rules of hypoglycaemia unawareness, then validation for driven licence is 3 years

Sweden: Not permitted for type 1 diabetes. Diabetes mellitus requiring insulin treatment constitutes grounds for denial of possession in groups II and III. However, if the disease is well-balanced, possession in category C may be granted. In such cases, possession shall be limited such that a heavy lorry may not be driven in traffic that is classified as commercial in the provisions of the Commercial Traffic Act (1998:490). In the case of diabetes mellitus treated with insulin, a reappraisal shall be made after one year and thereafter at least every third year

Sudan: No history of hypoglycaemia and diabetic retinopathy

United Arab Emirates: The restrictions are applicable to lorry or heavy machinery but not taxi drivers. Only applicable in Dubai but not in the other Emirates

United Kingdom: Restricted to one year licence with annual review by independent diabetologist. Need to show 3 months of blood tests (Some local authorities do not permit taxi drivers to be licensed if insulin-treated). For lorry drivers: annual review. No severe hypoglycaemia in that year. Evidence of regular monitoring (memory blood glucose meter). Visual acuity and fields as per EU driving regulations. Certification by diabetologist and specialist examiner Taxi drivers: as per car licence

Uzbekistan: The lorry and taxi drivers as well as drivers of public transport are examined each year and if the state of health allow them to work in normal mode (no progressive retinopathy, nephropathy or amputation) they can continue to exercise their usual job

*Each box above relates to a separate response. The response pertaining to the USA is given in the text.

Table 4 Comparison of two national socio/politico/economic indices (GDP and RTF)* in countries with and without restrictions on licensing for drivers on insulin therapy

Socioeconomic Indices

Gross Domestic Product (GDP) (million USD)

Road Traffic Fatality (RTF) rate (deaths/100,000 population)
Countries with no restrictions

$35,041(884-2,421,692)$

$18.5(3.5-73.4)$

GDP and RTF calculations are based on global data published by the World Bank for 2015 and the World Health Organisation for $2013^{14,15}$

* Median (range); ** Mann-Whitney U test
Countries with restrictions

$238,020(851-17,946,996)$

$10.3(3.0-29.0)$

\section{Statistics**}

Z-Score $=-3.277$ $\mathrm{p}=0.001$

Z-score $=2.66$ $\mathrm{p}=0.008$ 
vehicle accidents. As a consequence, in many countries, the medical profession, governmental transport authorities and vehicle licensing regulators have introduced measures to assess medical fitness to drive and restrict licensing for those at high risk. ${ }^{1,8-11}$ To protect public safety, legislation is in place in most countries in the developed world with respect to drivers with relevant medical conditions, and methods are used to identify and restrict individual drivers who are considered to constitute an increased accident risk. ${ }^{8-10}$ The nature of the legislation and restrictions on driving licences are similar in most parts of the western world and have evolved as knowledge of the potential risks of specific medical disorders has increased. .10 $^{8}$ One such example is the modified driving regulations for drivers with diabetes that were reviewed and published by the European Union in 2006, which were then revised and updated in 2009 prior to implementation by member states. ${ }^{16-18}$

From a global perspective, the situation regarding driving and diabetes does not mirror the position taken by western countries.2,12 A small survey in 1993 revealed that any form of assessment, licensing and regulation of drivers with insulin-treated diabetes is absent in many countries, even for drivers of large goods vehicles and passenger-carrying vehicles, which have the potential to cause serious physical injury or death to passengers or other road users if involved in a crash. When the previous international survey examined the licensing policies applied to professional (vocational) lorry drivers with insulin-treated diabetes, the responses from 24 countries revealed that regulations differed widely, ranging from a complete ban on professional driving to (more commonly) no restrictions whatsoever. ${ }^{11}$ Various reasons were proposed at that time to explain the differences in policies between countries, including the lack of an evidence base for the frequency of hypoglycaemia-induced road traffic accidents, particularly for commercially-driven vehicles. However, in many regions of the world, driving safety is not a priority despite the toll that road traffic accidents exert in terms of mortality and morbidity, and many countries appear to lack the necessary infrastructure and resources to undertake routine assessment of medical fitness to drive (for any medical disorder) of applicants for driving licences. ${ }^{11} \mathrm{~A}$ dearth of information is available about the regulations and practices with regard to driving and diabetes in many regions other than in North America, Europe and Australia. 2,12

The present survey is timely as the prevalence of diabetes is rising steeply worldwide, ${ }^{19}$ and particularly in many underdeveloped regions that have poor or limited access to diabetes education and support yet depend heavily on motor transport. ${ }^{20-26}$ In planning the survey it was thought that the IDF member organisations would be the most readily accessible sources of information about local practices and policies for driving and diabetes. However, although easily contactable, the overall response rate was limited, despite the fact that member organisations purport to have a primary interest in the welfare of people with diabetes in their countries. In some global regions responses were more often received from invited experts than from representatives of IDF member organisations. It is unknown whether a failure to respond was related to a reluctance to reveal the lack of regulation and review of medical fitness to drive in individual countries. However, information was obtained from 85 countries in different IDF regions, thus giving a reasonable overview of the current global situation. Comprehensive details on the regulations in Europe, North America and Australia are available online, but information on driving regulations is either absent or not readily available in many parts of the world.

While a questionnaire survey admittedly provides limited information, for the present survey the number of respondents was more than three times the number that participated in the 1993 survey. ${ }^{11}$ It provides insight into the current global position of regulations for driving and diabetes. The free text options allowed respondents to clarify their national situation, showing where differences exist (Table 3). Whereas it could be argued that approaching the statutory authorities such as transport ministries would have produced more valuable data than diabetes organisations and selected expert individuals, this may not be a reliable source of information for some countries in the developing world.

The present survey has revealed that, in most of the countries surveyed $(73 \%)$, no restrictions are imposed on drivers with insulin-treated diabetes and it can be surmised that the position is similar in those countries from which no information was forthcoming. Some form of medical examination was required in only one-third of the countries reviewed. When proscribed, they were performed at variable intervals, confirming a lack of consistency internationally regarding methods of assessment of medical fitness to drive and how often this should be undertaken. Although it can be argued that the basic assessment of medical fitness to drive can be made by a suitably trained physician, conditions such as insulin-treated diabetes require some degree of expert specialist input to ensure safe driving practices are being followed, particularly for vocational drivers. In 16 of the countries surveyed, medical assessment could be performed by anyone who was medically qualified and involvement of designated specialist physicians was much less frequent (10 of the 85 countries). There was an emphasis on reviewing risk to driving safety by the identification of specific problems such as the frequency of hypoglycaemia and the presence of visual deficits, impaired hypoglycaemia awareness, diabetic neuropathy and neuromuscular incoordination. However, a recent survey of physicians in the Gulf region demonstrated variable perceptions of the medical aspects of fitness to drive, ${ }^{27}$ and an international study of the quality of national-level guidelines for determining medical fitness to drive demonstrated substantive variability in the quality of these guidelines, and rigour of development has been shown to be a relative weakness. ${ }^{28}$

When a driver's treatment has to be changed to insulin, in most countries the driver is allowed to continue to drive without any alteration to licensing entitlements; only a few countries require specific criteria to be met before a driver commencing insulin therapy is allowed to retain the driving licence. With respect to licensing individuals with insulin-treated diabetes to drive vehicles that are associated with higher safety risk, such as large goods vehicles and vehicles carrying passengers, this is permitted 


\section{Key messages}

- A survey of 85 countries revealed a wide variation between different countries and global regions

- No restrictions on drivers with insulin-treated diabetes existed in 59 (69.4\%) of the 85 countries. Medical assessment of some type was required in 29 countries (34.5\%) by different people and at different times

- A driver staring on insulin treatment can continue to drive without any change in licensing entitlement in 68 countries (80\%) and can retain the licence subject to special conditions in 16 countries (19\%)

- With respect to large goods vehicles and passengercarrying vehicles, no restrictions or assessments are required for drivers with insulin-treated diabetes in most responding countries ( $56 ; 66 \%)$; licensing is permitted with some restriction in 23 countries (27\%) and prohibited in 6 countries (7\%)

without any restriction in two-thirds of the countries surveyed. By contrast, driving these vehicles is forbidden in six countries. In only one-quarter of the countries surveyed is licensing subject to some restrictions and medical review.

Data have been presented for each IDF area separately as this is the conventional way of discussing global diabetes concerns. However, it could be argued that countries within each area may have little in common other than proximate geography. The insulin therapy-associated driving restriction was therefore examined using GDP and RTF rate per 100,000 population as two national indices of socioeconomic development and driving standards and safety, respectively. Although the findings may appear predictable, GDP was significantly lower in the countries with no restrictions than in those with restrictions and RTF was greater in the countries with no restrictions than in the countries with restrictions.

In conclusion, the present survey has revealed wide variations between different countries and international regions in statutory legislation, policies and practices to regulate drivers with diabetes. The situation does not appear to have changed or improved in the last two decades. A significant lack of concern and complacency appears to exist in many countries, in which no measures are being taken to protect the public and the drivers themselves. There is a clear dichotomy in the current approach and practice between developed and developing countries. Drawing from the experience gathered from the work on establishing guidelines on definitions, diagnosis and management in diabetes by the WHO and the IDF, there is a major need to highlight the potential problems associated with driving and diabetes and to encourage individual governments to adopt methods to assess and review medical fitness to drive for people who are being treated with insulin. It would be possible to share experiences and methodologies between different regions of the world. Model guidelines and regulations could be developed internationally and shared with national organisations. This important issue requires the active participation of major diabetes bodies such as the IDF to promote awareness of the risks of driving and diabetes and to attempt to tackle this problem on a global basis.

Acknowledgement The authors are grateful for all respondents who answered the survey questions.

\section{Conflict of interest None}

\section{Funding None}

Authors' contributions SAB initiated the research. SAB, WSB, SY and $A S B$ executed the survey. $S A B$ drafted the manuscript and BMF revised the manuscript and provided more references. All authors reviewed the data and approved the final version of the manuscript.

\section{References}

1. World Health Organization. Global status report on road safety 2013: supporting a decade of action. Available at: www.who.int (accessed 30 July 2015).

2. Graveling AJ, Frier BM. Driving and diabetes: problems, licensing restrictions and recommendations for safe driving. Clin Diabetes Endocrinol 2015;1:8 http://dx.doi.org/10.1186/s40842-015-0007-3

3. Inkster B, Frier BM. Diabetes and driving. Diabetes Obes Metab 2013;15:775-83. https://doi.org/10.1111/dom.12071

4. American Diabetes Association, Lorber D, Anderson J, Arent S, et al. Diabetes and driving. Diabetes Care 2012;35(Suppl 1):S81-6. http://dx.doi.org/10.2337/dc12-s081

5. Cox DJ, Gonder-Frederick L, Clarke W. Driving decrements in type I diabetes during moderate hypoglycemia. Diabetes 1993;42:239-43. https://doi.org/10.2337/diab.42.2.239

6. Cox DJ, Gonder-Frederick LA, Kovatchev BP, Julian DM, Clarke WL. Progressive hypoglycemia's impact on driving simulation performance. Occurrence, awareness and correction. Diabetes Care 2000;23:163-70. https://doi.org/10.2337/diacare.23.2.163

7. Cox DJ, Gonder-Frederick LA, Kovatchev BP, Clarke WL. The metabolic demands of driving for drivers with type 1 diabetes mellitus. Diabetes Metab Res Rev 2002;18:381-5. https://doi.org/10.1002/dmrr.306

8. DVLA. At a glance guide to the current medical standards of fitness to drive. Drivers Medical Group, DVLA, Swansea, UK. 2014. Available at: www.gov.uk (accessed 30 July 2015).

9. Road Safety Authority. Medical fitness to drive guidelines. Available at: www.rsa.ie (accessed 30 July 2015).

10. Austroads. Assessing fitness to drive for commercial and private vehicle drivers. National Transport Commission, Australia. Available at: www.onlinepublications.austroads.com.au (accessed 30 July 2015).

11. DiaMond Project Group on Social Issues. Global regulations on diabetic treated with insulin and their operation of commercial motor vehicles. BMJ 1993;307(6898):250-3. https://doi.org/10.1136/bmj.307.6898.250

12. Beshyah SA, Lakhdar AF. Medical aspects of fitness to drive in the developing world: Time to act! Ibnosina J Med BS 2015;7:37-41.

13. Hassoun AA, Abdella N, Arouj MA, et al. Driving and diabetes mellitus in the Gulf Cooperation Council countries: call for action. Diabetes Res Clin Pract 2015;110:91-4. http://dx.doi.org/10.1016/j.diabres.2015. 08.002

14. World Bank. World Development Indicators database, 22 July 2016. Available at: http://databank.worldbank.org/data/download/GDP.pdf (accessed 1 August 2016).

15. World Health Organization. Road traffic death rate by WHO region and income level, 2013. Available at: http://apps.who.int/gho/data/ node.main.A997 (accessed 1 August 2016).

16. The European Parliament and the Council of the European Union. Directive 2006/126/EC of the European Parliament and of the Council of 20 December 2006 on driving licences. Off J Eur Union 2006;L403:1860.

17. The European Parliament and the Council of the European Union. Commission Directive 2009/113/EC of 25 August 2009 amending Directive 2006/126/EC of the European Parliament and of the Council on driving licences. Off J Eur Union 2009;L223:31-5. 
18. Kilpatrick ES, Rigby AS, Warren RE, Atkin SL. Implications of new European Union driving regulations on patients with type 1 diabetes who participated in the Diabetes Control and Complications Trial. Diabet Med 2013;30:616-19. http://dx.doi.org/10.1111/dme.12075

19. Guariguata L, Whiting DR, Hambleton I, Beagley J, Linnenkamp U, Shaw JE. Global estimates of diabetes prevalence for 2013 and projections for 2035. Diabetes Res Clin Prac 2014;103:137-49. http://dx.doi.org/10.1016/j.diabres.2013.11.002

20. Jadaan KS, Bener A, Al-Zahrani A. Some aspects of road user behaviour in selected Gulf Countries. J Traffic Med 1993;20:143-8.

21. Qayed MH. Epidemiology of road traffic accidents in Al- Ahssaa Governorate, Saudi Arabia. Saudi Med J 1998;4:513-19.

22. Ansari S, Akhdar F, Madoorah M, Mutaery K. Causes and effects of road traffic accidents in Saudi Arabia. Public Health 2000;114:37-9. https://doi.org/10.1016/S0033-3506(00)00306-1

23. Ofosu JB, Abouammoh AM, Bener A. A study of road traffic accidents in Saudi Arabia. Accid Anal Prev 1988:20:95-101. https://doi.org/10.1016/0001-4575(88)90024-3

24. Ministry of Interior, Directorate of Traffic, United Arab Emirates. Road Traffic Accident, Statistics Annual Report. UAE: MOI, Directorate of Traffic, 1998

25. Jadaan KS. Traffic safety in Gulf countries with special reference in Kuwait. Transport Reviews 1988;8:249-65. https://doi.org/10.1080/01441648808716690

26. Bener A, Abu-Zidan FM, Bensiali AK, Al-Mulla AAK, Jadaan KS. Strategy to improve road safety in developing countries. Saudi Med 2003;24:603-08

27. Beshyah SA, Beshyah WS, Yaghi S, Beshyah AS, Faroogi MH, Lakhdar AA. Perceptions of health care professionals of medical aspects of driving safety: an electronic survey. Ibnosina J Med BS 2015;7:169-75.

28. Rapoport MJ, Weegar K, Kadulina Y, et al. An international study of the quality of national-level guidelines on driving with medical illness. QJM 2015;108:859-69. http://dx.doi.org/10.1093/qjmed/hcv038

\section{MINIMED $^{\text {Th }} 640 \mathrm{G}$ A BREAKTHROUGH SYSTEM}

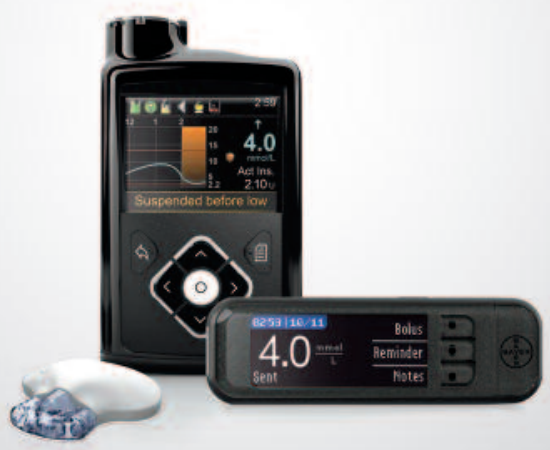

MINIMED ${ }^{\mathrm{TM}} 640 \mathrm{G}$ SYSTEM COMBINES: ADVANCED PROTECTION PERSONALISED CONVENIENCE IMPROVED DESIGN 